AÇÃO MIDIÁTICA, n.17. Jan./Jun. 2019. Curitiba. PPGCOM-UFPR. ISSN 2238-0701

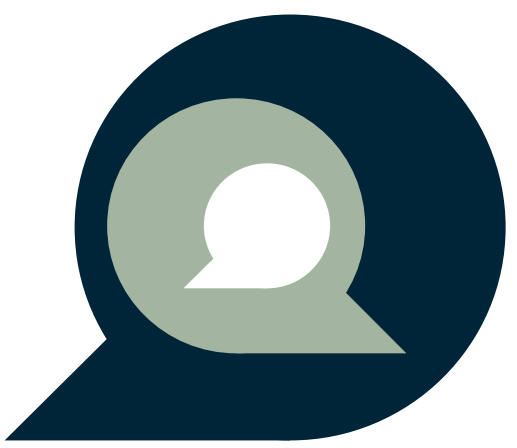




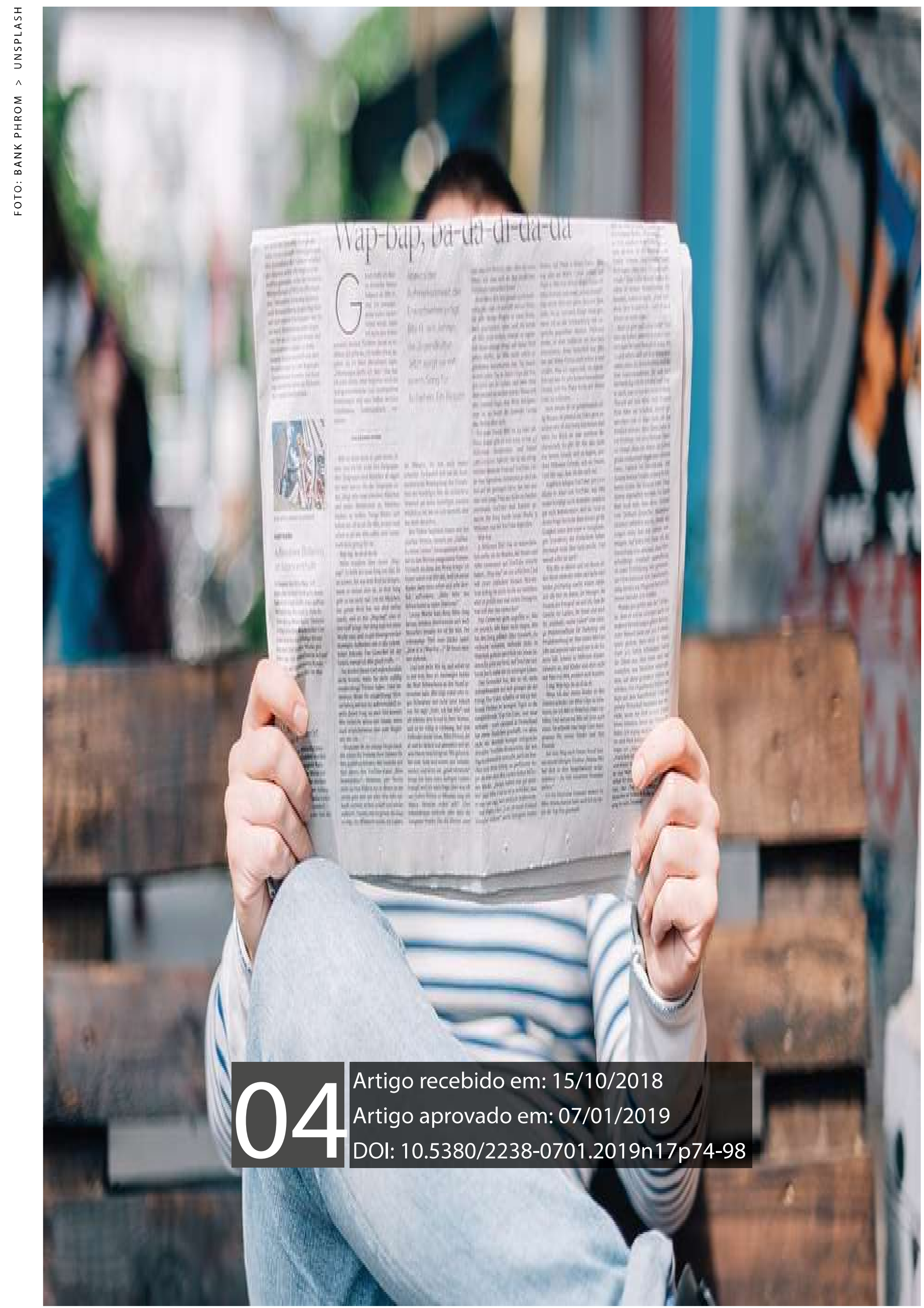


Utilização do projeto \#doleitorZH como instrumento participativo no Instagram da marca Zero Hora (@gauchaZH) 


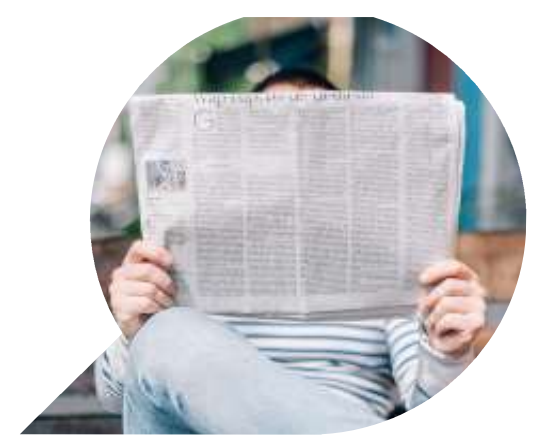

\section{Utilização do projeto \#doleitorZH como instrumento participativo no Instagram da marca Zero Hora (@gauchaZH) ${ }^{1}$}

Utilización del proyecto \#doleitorZH como instrumento participativo en el Instagram de la marca Zero Hora (@gauchaZH)

Using the \#doleitorZH project as a participatory tool in the
Zero Hora brand Instagram (@gauchaZH)

IVAN BONFIM ${ }^{2}$

\section{LARISSA CANTUÁRIA LUCENA ${ }^{3}$}

Resumo: O presente artigo pretende refletir sobre o emprego do projeto \#doleitorZH, idealizado desde 2012 pela marca Zero Hora (@gauchaZH), como ferramenta jornalística participativa no Instagram. A empresa de comunicação analisada costuma interligar os seus conteúdos em múltiplas plataformas - jornal impresso, jornal digital, aplicativo para dispositivos móveis e, mais recentemente, o site GaúchaZH, em parceria com a Rádio Gaúcha -,

1 O presente trabalho foi realizado com apoio da Coordenação de Aperfeiçoamento de Pessoal de Nível Superior - Brasil (Capes). Código de Financiamento 001.

2 Professor do Departamento de Jornalismo da Universidade Estadual de Ponta Grossa (UEPG), pós-doutor em Ciências da Comunicação pela Unisinos, doutor e mestre em Comunicação e Informação pela UFRGS. É um dos coordenadores do Grupo de Estudos e Pesquisas em Mídias Digitais (UEPG/ CNPq). E-mail: ivanbp17@gmail.com.

3 Bacharel em Jornalismo pela Universidade Federal do Amapá. Mestranda em Jornalismo pela Universidade Estadual de Ponta Grossa, com bolsa Capes. E-mail: larissacantuaria8@gmail.com. 
mostrando ter se adaptado ao contexto da convergência. Para chegar ao propósito, usou-se o método análise de conteúdo com a intenção de observar as apropriações dos usuários/leitores na rede social mencionada. Assim, os resultados indicam que ocorre a interação do público, sendo a maioria das publicações no feed do perfil @gauchaZH no aplicativo, durante o mês de novembro de 2017.

\section{Palavras-chave: Instagram; Zero Hora; Convergência.}

Resumen: El presente artículo pretende reflexionar sobre el empleo del proyecto \#doleitorZH, idealizado desde 2012 por la marca Zero Hora (@gauchaZH),como herramienta periodística participativa en el Instagram. La empresa de comunicación analizada suele interconectar sus contenidos en múltiples plataformas - periódico impreso, periódico digital, aplicación para dispositivos móviles y, más recientemente, el sitio GaúchaZH, en sociedad con Rádio Gaúcha-, mostrando haberse adaptado al contexto de la convergencia. Para llegar al propósito, se utilizó el método análisis de contenido con la intención de observar las apropiaciones de los usuarios/lectores en la red social mencionada. Así, los resultados indican que ocurre la interacción del público, siendo la mayoría de las publicaciones en el feed del perfil @gauchaZH en la aplicación, durante el mes de noviembre de 2017.

Palabras clave: Instagram; Zero Hora; Convergencia.

Abstract: This article intends to reflect on the use of the \#doleitorZH project, idealized since 2012 by the brand Zero Hora (@gauchaZH), as a participatory journalistic tool in Instagram. The analyzed communication company usually interconnects its contents in multiple platforms - printed newspaper, digital newspaper, mobile application and, more recently, the GaúchaZH website, in partnership with Rádio Gaucha -, showing that it has adapted to the context of convergence. To reach the purpose, the content analysis method was used with the intention of observing the appropriations of the users/readers in the mentioned social network. Thus, the results indicate that the interaction of the public occurs, with most publications in the profile feed @ gauchaZH in the application, during the month of November 2017. 
Keywords: Instagram; Zero Hora; Convergence.

\section{Introdução}

A internet desencadeou transformações que proporcionam novos modos de ser e estar no mundo, tanto individualmente quanto em conjunto, o que é refletido em distintas formas de experiências compartilhadas e relacionamentos, tendo impacto significativo nas possibilidades de interação entre atores (PRIMO, 2007; RECUERO, 2015). Neste contexto de modificações estruturais e estruturantes, o jornalismo busca adaptar-se às maneiras mais recentes de compartilhamento de notícias e interação com o público, tendo a presença de empresas de comunicação em aplicativos que permitem divulgar um conteúdo para diferentes usuários como, por exemplo, o Instagram.

Ao visualizar as potencialidades da plataforma para o âmbito jornalístico, o estudo objetiva compreender o funcionamento do projeto \#doleitorZH como instrumento participativo da marca Zero Hora (@ gauchaZH). O referido objeto foi escolhido por apresentar amplo engajamento nas três principais mídias digitais - Facebook ${ }^{4}$, Twitter ${ }^{5}$ e Instagram $^{6}$-, segundo o sistema Torabit ${ }^{7}$. Além do jornal impresso, o Zero Hora disponibiliza o jornal digital, aplicativo para dispositivos móveis e o site GaúchaZH ${ }^{8}$ (resultado da integração com a Rádio Gaúcha na internet), fazendo, então, parte do chamado contexto da convergência midiática (JENKINS, 2009) e convergência jornalística (SALAVERRÍA; GARCÍA AVILÉS; MASIP, 2010).

Com o intuito de atingir as finalidades do trabalho, realizou-se o levantamento bibliográfico sobre as características do Instagram (BARBALHO, 2011; PIRES, 2012; BATISTA, 2014; SILVA JÚNIOR, 2014; LISBOA; FREIRE, 2014; FERREIRA; PADILHA, 2014; VIERA, 2015; LUZ, 2018) e a marca Zero Hora (FELIPPI, 2006; LINDEMANN, 2014; GRUSZYNSKI; LINDEMANN; OLIVEIRA, 2014; GUIDOTTI, 2015, 2017; RUVIARO; BELOCHIO, 2017), além da utilização da análise de conteúdo como aporte metodológico para observar o perfil @gaucha-

\footnotetext{
4 <https://www.facebook.com/gauchazh/>. Acesso em: 15 de outubro de 2018.

5 <https://twitter.com/GauchaZH>. Acesso em: 15 de outubro de 2018.

6 < https://www.instagram.com/gauchazh/>. Acesso em: 15 de outubro de 2018.

7 <http://www.torabit.com.br>. Acesso em: 13 de outubro de 2018.

8 <https://gauchazh.clicrbs.com.br/>. Acesso em: 13 de outubro de 2018.
} 
$\mathrm{ZH}$, entre $1^{\circ}$ e 30 de novembro de 2017 , mês escolhido de forma aleatória para explorar e identificar o uso da rede social.

Nesta perspectiva, a estrutura do artigo apresenta sobre a dimensão imagética no jornalismo, as funções do Instagram com ênfase no fotojornalismo e a marca Zero Hora no ambiente digital. Nos procedimentos metodológicos, estão presentes os caminhos que a pesquisa percorreu para definir o objeto de estudo. E, para finalizar, traz a análise e interpretação dos dados encontrados durante o período de 30 dias, com enfoque para as 102 publicações encontradas a partir da categorização pela \#doleitorZH.

\section{A dimensão imagética no jornalismo}

Com o intuito de analisar o desenvolvimento jornalístico em relação ao Instagram, debate-se brevemente acerca da dimensão imagética. Remetendo ao filósofo Platão, Joly (2002, p. 14) afirma que a imagem "seria um objeto segundo com relação a um outro que ela representaria de acordo com certas leis particulares". Polissêmico, o termo engendra dois grandes domínios, de acordo com Aumont (2006): imagens imateriais (imagens mentais) e materiais, como representações visuais (fotografias, desenhos etc.). Importa salientar que a investigação de imagens materiais - como no caso ora apresentado - demanda trabalhar com a dimensão da percepção, ou seja, algo que possui dimensão biológica (o sentido da visão) e sociocultural (a interpretação do que se vê) em ininterrupta relação, permitida pela expressão de uma dimensão tecnológica (a materialidade).

Em maior ou menor grau, a imagem fia-se em uma semelhança com o objeto que busca representar e, ao final, no senso comum, a "realidade" é aquilo que os indivíduos veem, e essa consideração tem firmes bases em nossa predisposição de acreditar no que os olhos apreendem. As informações adquiridas pela visão são processadas a partir de sistemas simbólicos instituídos culturalmente: a operação perceptiva é trabalhada junto às ideologias, crenças, afetos, trajetória pessoal e ao Zeitgeist, representativo das convenções culturais, sociais e históricas mormente. Assim, não há imagem "pura" - nos dizeres de Aumont (2006), o observador constrói a imagem, e esta também constrói o observador.

Santaella e Nöth (2001) defendem a existência de três paradigmas 
no processo evolutivo de produção de imagem: pré-fotográfico, fotográfico e pós-fotográfico. No primeiro, predominam as feituras artesanais, que dão expressão à visão por meio de habilidades da mão e do corpo, como o desenho, a pintura, a gravura e a escultura; o segundo diz respeito a todas as imagens produzidas pela automatização da conexão dinâmica e captação da realidade, estendendo-se ao cinema, TV, vídeo e holograma; já o terceiro apresenta as imagens sintéticas ou infográficas, derivadas de matrizes numéricas inteiramente calculadas por técnicas de computação. Para os autores, o suporte de imagens do paradigma pós-fotográfico

[...] não é mais matérico como na produção artesanal, nem físico-químico e maquínico como na morfogênese ótica, mas resulta do casamento entre um computador e uma tela de vídeo, mediados ambos por uma série de operações abstratas, modelos, programas, cálculos. O computador, por sua vez, embora também seja uma máquina, trata-se de uma máquina de tipo muito especial, pois não opera sobre uma realidade física, tal como as máquinas óticas, mas sobre um substrato simbólico: a informação. (SANTAELLA; NÖTH, 2001, p. 166)

A fotografia jornalística possui caráter socialmente construído e construtor. Conforme Sousa (2000), ela promove uma vinculação estreita entre as imagens (representações visuais) e a concepção de realidade, visto que a noção de "aprisionamento do instante" incorre em níveis de realismo não alcançados pelas pinturas artísticas, por exemplo. Ponderando que não há uma gramática para a interpretação das representações visuais, com esse processo sendo determinado a partir de convenções amparadas por valores culturais, as possibilidades informativas que essas imagens carregam passam em grande escala pela constituição da moldura do que será visualizado junto à notícia e suas guias (como títulos, legendas e, no caso do Instagram, as hashtags). A imagem que vemos não é um fenômeno autogerado, mas uma instituição fruto de objetivos definidos, com uma configuração particular. Como aponta esconder-se sob a ideia de evidência, como se a representação visual se bastasse a si mesma, excluindo elementos subjetivos. 


\section{O Instagram como espaço para o jornalismo}

Desde os anos 1990, com o início da internet comercial, o jornalismo tem buscado desenvolver formas de apropriação e interação no ambiente digital. Esse espaço de construção de identidade, formação e fortalecimento de laços tornou-se uma ferramenta na difusão e circulação de informações, ao considerar as funcionalidades do compartilhamento de imagens, textos, vídeos e links. As modificações trazidas pela chamada Web 2.0, na qual sites, plataformas e processos têm grande parte de sua lógica baseada na interação e sociabilidade (PRIMO, 2007), afetam significativamente os meios jornalísticos, influenciando produção, distribuição e circulação dos produtos noticiosos.

Neste contexto contemporâneo, diversas redes sociais passaram a existir, com diferentes angulações e objetivos - e ocasionando novos processos de sociabilidade. Criado pelos engenheiros de software Kevin Systrom e Mike Krieger, o Instagram surgiu em outubro de 2010, voltado exclusivamente para o sistema operacional desenvolvido pela Apple, o iOS. Em abril de 2012, a plataforma foi disponibilizada para os usuários do sistema operacional Android e, no mesmo mês, vendida para o Facebook por 1 bilhão de dólares. A popularidade do aplicativo cresceu tanto que, em 2017, chegou à marca de 700 milhões de usuários ativos, sendo o Brasil o segundo país com mais instagramers no mundo, com 45 milhões de usuários ${ }^{9}$.

Batista (2014) explica que o nome Instagram vem da fusão entre os termos instant ("instante") e telegram ("telegrama"), remetendo a ideia de compartilhar uma fotografia no momento em que ela foi realizada. "Sua principal inspiração foram as câmeras Polaroid, que ficaram famosas por imprimir fotografias no momento em que eram tiradas" (BATISTA, 2014, p. 34). A plataforma permite produzir e publicar fotografias e vídeos por meio de um perfil, seguidos de legendas, e possibilita que seus usuários possam curtir e comentar as publicações e também interagir $^{10}$ nas chamadas mensagens diretas. Por isso, é considerada uma

9 Disponível em: <https://canaltech.com.br/redes-sociais/instagram-chega-a-700-milhoes-de-usuarios-e-tem-crescimento-historico-92798/>. Acesso em: 30 de janeiro de 2018.

10 É necessário comentar as perspectivas de interação contempladas pelos autores Recuero (2009) e Primo (2007). A primeira aponta que os processos interacionais conformam, via de regra, estrutura social e dimensão comunicativa, sendo que os interagentes de um cenário de interação objetivam colocar diferentes compreensões, cujos efeitos podem incluir novas informações e uma gama de consequências (ações e reações), intencionadas ou não. Já a segunda analisa as interações mediadas por computador, que constituem e estruturam relações entre interagentes permitidas pelos avanços 
rede social da internet, segundo o conceito de Boyd e Ellison citado por Recuero (2009).

Sites de redes sociais foram definidos por Boyd \& Ellison (2007) como aqueles sistemas que permitem i) a construção de uma persona através de um perfil ou página pessoal; ii) a interação através de comentários; e iii) a exposição pública da rede social de cada ator. (RECUERO, 2009, p. 102)

As redes sociais caracterizam-se pela tendência de privilegiar modelos visuais. Mesmo nos blogs, definidos como compartilhamento de textos, publicações concisas com fotografias e imagens evidenciam-se das demais, pois "explodiram na web como o formato que mais atrai o olhar e a atenção dos usuários, tornando-se preferência do público", sustenta Batista (2014, p. 16). A popularização dos dispositivos ${ }^{11}$ móveis que apresentam câmeras, explana o autor, facilitou a técnica de fotografar, tanto para o usuário comum quanto para um profissional da área da comunicação. E a proximidade do público com a fotografia ainda se dá pela praticidade do compartilhamento de dados nas mídias digitais.

O Instagram, para Silva Júnior (2014), influencia na relação entre a fotografia e a sociedade atual, que olha de forma simultânea para imagens que remetem ao banal e ao significativo. $\mathrm{O}$ aspecto mais marcante do aplicativo "parece ser o eixo que ele configura entre o modo de se fazer e o modo de ver fotografias. Ou seja, atua na base da própria forma da fotografia, se compreendermos esta como a comunicação entre o modo de se clicar e de se consumir/acessar" (SILVA JÚNIOR, 2014, p. 98).

Os fotógrafos têm oportunidade de divulgar seu trabalho na plataforma e, para obter destaque e atrair seguidores, usam a criatividade na organização de suas publicações, seguindo uma característica mais

da tecnologia (como as plataformas de redes sociais), sendo que estas ocorrem em um ambiente virtualizado, mas que têm implicações claras na sociedade - diluindo a antiga perspectiva de distinção entre "real" e "virtual". Um exemplo são as interações mútuas e as reativas protagonizadas pelos interagentes: aquelas se mostram interdependentes, com os participantes buscando sentidos de cooperação e afetando-se mutuamente; no que tange às reativas, mostram-se pré-determinadas, como o caminho seguido pelo usuário a partir do clique em um hyperlink.

11 Cabe dizer que o conceito de dispositivo engendra mediações situacionais e tecnológicas, segundo Ferreira (2002, p. 1), ademais de "aspectos discursivos, normativos, simbólicos, funcionais e referenciais que incidem nas interações, no tempo e espaço, propiciadas pela conexão de suportes tecnológicos". 
individual. Lisboa e Freire (2014, p. 136) discorrem que "a volatilidade das imagens traz à tona a necessidade de reconstruções estéticas e formatações diferenciadas do discurso visual, sobretudo por conta de sua relação com as novas mídias, em especial com os dispositivos móveis".

Importante afirmar também que o aplicativo desenvolveu uma apresentação inovadora. Ele popularizou o que antes era possível apenas nos programas de edição: adicionar efeitos pré-definidos às fotos com coloração, desfoque, brilho e borda. A presença dos filtros foi primeiro atributo a que se deve o sucesso da mídia. Pires (2012) diz que esses recursos dão um ar poético aos registros cotidianos, pois produzem efeitos das câmeras analógicas, como a Polaroid e a Lomo.

O imediatismo do clique, a mobilidade dos smartphones e tablets, a narrativa das imagens como ponto-de-vista, somadas a possibilidade de pós-produção da imagem no aplicativo, conferem às fotografias compartilhadas nessa rede social, uma estética que não funciona em outras redes. (PIRES, 2012, p. 59)

A plataforma passou por várias mudanças nos últimos anos. Em 2012, lançou a página oficial no formato $\mathrm{web}^{12}$, "o que facilitou e alternou a possibilidade de consumir o conteúdo da rede social" (LUZ, 2018, p. 42). A ferramenta conhecida como Instagram Stories, incorporada ao aplicativo em 2016, surgiu para compartilhar fotos e vídeos personalizados que desapareciam depois de 24 horas da sua publicação, mas a atualização de novembro de 2017 trouxe a opção de criar um highlight ("destaque") com os stories ("histórias") que ficarão fixados por tempo indeterminado no perfil do usuário.

Tendo em vista as potencialidades do Instagram, o aplicativo vem se configurando como um relevante instrumento na relação direta dos meios de comunicação com o público, além de servir para divulgar o conteúdo produzido na redação. Guidotti (2015) menciona que o uso das hashtags ${ }^{13}$, por exemplo, assegura o monitoramento das publicações pela utilização de palavras-chave, servindo para o rastreamento sobre determinado tema, como eventos ou catástrofes naturais. A geolocaliza-

12 Apesar da novidade, as publicações no Instagram continuam exclusivas aos smartphones e tablets, demonstrando que os dispositivos móveis permanecem sendo o foco da rede social.

13 Hashtag é uma palavra-chave antecedida pela cerquilha (\#) utilizada para categorizar os conteúdos publicados nas redes sociais. 
ção também é uma função muito útil para os profissionais de comunicação, uma vez que é possível fazer check-in no local onde a publicação foi registrada e, assim, conectar-se aos múltiplos olhares sobre o mesmo lugar. O compartilhamento e intercâmbio com diferentes plataformas, como Facebook, Twitter e Tumblr, é outra particularidade do Instagram que ajuda a expandir o alcance da mensagem.

Os vídeos e as transmissões ao vivo - formatos de conteúdo mais recentes incorporados à rede social - são outros recursos que facilitam a cobertura jornalística. Barbalho (2011) declara que, ao se unir com outras mídias, a fotografia mantém seu papel de destaque oferecido pelas novas tecnologias.

A diferença é que as fotografias, acompanhadas anteriormente apenas de pequenos textos e legendas e inseridas em um projeto gráfico compatível com a proposta do foto-ensaio nas revistas ilustradas, aparecem no jornalismo online intercaladas a imagens de vídeo e áudio. Isso torna a reportagem fotográfica contemporânea mais complexa e multiforme, uma espécie de objeto multimídia. Estamos, portanto, mais uma vez diante de um novo fotojornalismo? (BARBALHO, 2011, p. 11)

Sabendo que a rede social se tornou um importante canal para jornalistas e produtores de conteúdo, a equipe do Instagram criou uma página exclusiva à imprensa ${ }^{14}$. Nesta, consta a atualização das principais notícias sobre a plataforma e há uma linha do tempo descrevendo a história da empresa. Com isso, percebe-se a aproximação da rede social com os veículos de comunicação, influenciando no engajamento do público que consome a informação.

\section{Zero Hora no ambiente digital}

Antes, porém, de discutirmos sobre a utilização da marca Zero Hora no meio virtual, faz-se necessária a compreensão de convergência apresentada por Jenkins $(2009$, p. 29), que se refere "ao fluxo de conteúdos através de múltiplas plataformas de mídia, à cooperação entre múltiplos mercados midiáticos e ao comportamento migratório dos públicos dos meios de comunicação". O autor aborda o fenômeno a partir de um viés

14 <https://instagram-press.com/>. Acesso em: 14 de outubro de 2018. 
cultural, considerando a variedade de relações sociais, econômicas e materiais relativas à produção e consumo das mídias.

A partir dessa definição, de acordo com Salaverría, García Avilés e Masip (2010), compreendemos a convergência jornalística como

Um processo multidimensional que, facilitado pela implantação generalizada das tecnologias digitais de telecomunicação, afeta o âmbito tecnológico, empresarial, profissional e editorial dos meios de comunicação, propiciando uma integração de ferramentas, espaços, métodos de trabalho e linguagens anteriormente separados, permitindo que os jornalistas elaborem conteúdos para serem distribuídos através de múltiplas plataformas, mediante as linguagens próprias de cada uma. (SALAVERRÍA; GARCÍA AVILÉS; MASIP, 2010, p. 59, tradução nossa) ${ }^{15}$

Portanto o Zero Hora é um exemplo relevante de empresa de comunicação que se adaptou ao processo da convergência, visto que costuma interligar os seus conteúdos em múltiplas plataformas com objetivo de criar novas relações entre jornalistas e audiências. Integrante do Grupo Rede Brasil Sul de Comunicação (RBS) ${ }^{16}$, a marca conquistou credibilidade com seu jornal impresso diário ${ }^{17}$, primeiro produto a circular com o nome "Zero Hora", em 4 de maio de 1964 (GRUSZYNSKI; LINDEMANN; OLIVEIRA, 2014). No ano de 1995, lançou o seu primeiro site na internet, substituindo a página estática do periódico pelo portal Zero Hora.com em 2007.

Gruszynski, Lindemann e Oliveira (2014) sintetizam que, em 2009, a marca tornou-se acessível aos tablets e smartphones por intermédio da mídia Kindle e, em 2011, lançou seu aplicativo para os sistemas iOS, Android e BlackBerry. No mesmo ano, também reformulou seu site com a implementação de um novo sistema de gerenciamento de conteúdo, sendo algumas das iniciativas que aperfeiçoaram a distribuição em

15 Tradução livre do original: "un proceso multidimensional que, facilitado por la implantación generalizada de las tecnologías digitales de telecomunicación, afecta al ámbito tecnológico, empresarial, profesional y editorial de los médios de comunicación, propiciando una integración de herramientas, espacios, métodos de trabajo y lenguajes anteriormente disgregados, de forma que los periodistas elaboran contenidos que se distribuyen a través de múltiplas plataformas, mediante los lenguajes propios de cada una" (SALAVERRÍA; GARCÍA AVILÉS; MASIP, 2010, p. 59).

16 Conglomerado de mídia que, desde 1957, atua no Rio Grande Sul. 0 grupo esteve presente em Santa Catarina durante 37 anos, vendendo seus veículos em 2016.

17 Mesmo focado estrategicamente em seu estado de circulação, o jornal é um dos mais expressivos do país. Segundo pesquisa da Associação Nacional de Jornais, o veículo ocupou a sexta posição no ranking de jornais mais vendidos no Brasil em 2015. 
diferentes plataformas. Em 2012, cada editoria passou a ser responsável pela cobertura e produção simultânea para as edições impressa e online. Em 2015, implementou o ZH Jornal Digital, com versão para desktop e mobile ${ }^{18}$.

Ao citar sobre as transformações ocorridas na redação do periódico estudado, pontuamos as observações de Jenkins (2009, p. 326) sobre a influência da convergência na atuação da indústria midiática: "Quaisquer que sejam as motivações, a convergência está mudando o modo como os setores da mídia operam e o modo como a média das pessoas pensam sobre sua relação com os meios de comunicação".

Até então familiarizados apenas com o impresso, os repórteres e editores tiveram que pensar também na produção audiovisual, afirmam Gruszynski, Lindemann e Oliveira (2014). O conteúdo deveria seguir um design pré-estabelecido, conforme restrições dos softwares de produção e publicação online. A partir disso, a interatividade passou ser um elemento obrigatório, cuja apropriação acarretou em mudanças que resultaram na criação do editor de mídias sociais.

Vemos, portanto, que as iniciativas de ZH são moldadas, essencialmente, pela tecnologia - o que representa mudanças nas rotinas produtivas e nos produtos criados pela empresa para serem ofertados ao público. Contudo, tais processos não podem ser vistos apenas a partir deste viés, o qual coloca o jornal como precursor em diversos momentos, mas também se faz necessário considerar a lógica instrumental, pela qual o jornal tem interesses próprios, fundamentados no polo econômico do jornalismo enquanto negócio. (GRUSZYNSKI; LINDEMANN; OLIVEIRA, 2014, p. 3)

É oportuno esclarecer que, para as autoras citadas acima, as regras que regem as rotinas produtivas estão, sobretudo, subordinadas a lógicas comerciais. "Iniciativas do jornal $\mathrm{ZH}$ representam um avanço da empresa em conformidade com as tendências do mercado impostas pela evolução tecnológica, evidenciando a imersão do jornal no processo de convergência" (GRUSZYNSKI; LINDEMANN; OLIVEIRA, 2014, p. 3-4).

18 Disponível em: <https://gauchazh.clicrbs.com.br/geral/noticia/2015/11/baixe-o-novo-aplicativo-do-jornal-digital-de-zh-4918877>. Acesso em: 30 de janeiro de 2018. 
Apesar do propósito vinculado ao viés econômico, o veículo adotou como prioridade entregar o conteúdo de forma diferenciada, variando de acordo com a particularidade de cada mídia (Facebook, Twitter e Instagram). "Sabemos que muitos leitores utilizam o feed das redes sociais para se manter atualizados e, por isso, levamos muito a sério esse canal de distribuição", explica Sabrina Passos, gerente de produto digital do Zero Hora, em entrevista ao portal Meio \& Mensagem ${ }^{19}$.

O uso criativo da empresa na web rendeu o prêmio de Melhor Uso de Redes Sociais, no Global Media Awards da International News Media Association (INMA), em maio de 2017. Além de acompanhar o comportamento do leitor e ampliar a presença da marca, as mídias online têm, para o Zero Hora, a função de apoiar as pautas e os assuntos que serão abordados pelos jornalistas. Em setembro do mesmo ano, o jornal Zero Hora integrou-se com a Rádio Gaúcha na internet, lançando o GaúchaZH (www.gauchazh.com). A unificação dos sites também levou à mudança nas redes sociais de @zerohoraRBS para @gauchaZH. A versão impressa do periódico e a transmissão da rádio continuaram existindo de forma independente.

\section{Procedimentos metodológicos}

$\mathrm{Na}$ primeira etapa da pesquisa foi realizado um mapeamento para identificar qual veículo de comunicação que mais se destaca no Instagram, conforme o sistema Torabit, que produz mensalmente um ranking nacional de acordo com monitoramento, análise e mobilização nas redes sociais. A partir da averiguação, descobriu-se que o Zero Hora teve o maior engajamento nas três principais mídias digitais - Facebook, Twitter e Instagram - no primeiro semestre de $2017^{20}$, considerando a quantidade de interações do público com as postagens, seja via comentários, compartilhamentos ou curtidas.

Após as informações obtidas, como o trabalho pretendia compreender sobre as funcionalidades do Instagram, surgiu a necessidade de fazer uma pré-análise sobre o perfil @gauchaZH, quando se teve conhecimento do projeto denominado \#doleitorZH, instrumento criado desde 2012 para a empresa interagir com o seu público. Nessa plataforma, o Zero Hora tem 381 mil seguidores e 9.366 19 Disponível em: <http://www.meioemensagem.com.br/home/midia/2017/07/20/os-segredos-digitais-do-zero-hora.html>. Acesso em: 03 de fevereiro de 2018.

20 No primeiro semestre de 2017, o Zero Hora possuiu a maior taxa de engajamento em fevereiro, março, abril, maio, junho, julho e agosto; ficando em segundo lugar apenas em janeiro. 
publicações $^{21}$.

Depois de definido o corpus empírico, iniciamos a segunda etapa da pesquisa: monitoramento dando atenção às apropriações que os usuários/leitores fazem do perfil no Instagram por meio da \#doleitorZH. A verificação foi realizada segundo a metodologia análise de conteúdo proposta por Bardin (2011, p. 47), com intuito de "obter, por procedimentos sistemáticos e objetivos de descrição do conteúdo das mensagens, indicadores (quantitativos ou não) que permitam a inferência de conhecimentos relativos às condições de produção/ recepção (variáveis inferidas) destas mensagens".

A partir de um roteiro de observações contendo questões que apreciam a utilização de fotos e vídeos do público online da empresa Zero Hora, dividimos as categorias e variáveis da seguinte maneira: cenário (paisagens naturais ou espaços urbanos); perfil dos autores (profissionais ou amadores); estado (Rio Grande do Sul, São Paulo ou Santa Catarina); geolocalização e outras hashtags (se utiliza ou não esses recursos).

\section{Análise de interpretação dos dados}

O perfil no Instagram da marca Zero Hora foi visitado diariamente durante o período analisado, entre $1^{\circ}$ e 30 de novembro de 2017, no qual se catalogou um total de 197 mídias publicadas, sendo 188 fotos, quatro vídeos e cinco boomerangs ${ }^{22}$. Destas, 100 fotos e dois vídeos estão categorizados pela \#doleitor $\mathrm{ZH}$, além de cinco fotos pela \#doleitorZHpelomundo. Com isso, constatamos que o veículo prioriza os conteúdos oriundos da estratégia de interação com os usuários, incentivando a participação do seu público com a seguinte mensagem na biografia: "Compartilhe com a gente as suas fotos usando a tag \#doleitorZH”.

21 Acesso em: 14 de outubro de 2018.

22 O Boomerang é um aplicativo que tira várias fotos em sequência e usa as imagens para criar uma espécie de vídeo animado. Embora seja parecido com o GIF, o Boomerang não tem começo, meio e fim, como em uma animação convencional. 
Tabela 1: Distribuição das publicações no perfil @gauchaZH em novembro de 2017

\begin{tabular}{|l|l|l|l|l|}
\hline & Fotos & Vídeos & Boomerangs & Total (\%) \\
\hline \#doleitorZH & 100 & 2 & & $102(52 \%)$ \\
\hline \#doleitorZHpelomundo & 5 & & & $5(2 \%)$ \\
\hline Divulgação da marca & 51 & & & $51(26 \%)$ \\
\hline Bastidores da equipe & 18 & 2 & 5 & $25(13 \%)$ \\
\hline Paisagens 9 & & & & $9(5 \%)$ \\
\hline Eventos culturais & 9 & & & $3(1 \%)$ \\
\hline Esporte & 3 & & & $2(1 \%)$ \\
\hline Total (\%) & 2 & $4(2 \%)$ & $5(3 \%)$ & $197(100 \%)$ \\
\hline
\end{tabular}

Fonte: elaborado pelos autores.

Conforme observado na tabela acima, encontramos 51 imagens divulgando a marca, sendo 26 capas do jornal impresso e 25 capas do jornal digital; 24 publicações de bastidores do trabalho da equipe do jornal e do rádio, sendo 18 fotos, dois vídeos e cinco boomerangs; além de nove imagens de paisagens, três sobre eventos culturais e duas relacionadas ao esporte. Consideramos, portanto, que o perfil @gauchaZH não utiliza o feed para transmissão de notícias, preferindo disseminar os conteúdos jornalísticos no Instagram Stories (RUVIARO; BELOCHIO, 2017), já que a ferramenta permite o compartilhamento de links.

Em relação ao projeto \#doleitor $Z H$, a interação e transmissão de conteúdos acontece por meio de publicações enviadas pelo público do jornal, criando pequenas comunidades virtuais no Instagram. Com os atores presentes no processo convergente, "as audiências têm variadas possibilidades de encontrar as informações desejadas e, mais do que isso, parte deste grupo tem interesse em participar e anseia por ver suas produções publicadas" (LINDEMANN, 2014, p. 60). 
O projeto \#doleitorZH é o segundo canal desenvolvido para aproximar a empresa com o seu público no Instagram. O primeiro, chamado de \#missãoZH, solicitava que os usuários enviassem as fotos de acordo com temas previamente definidos pela equipe do jornal. A cada sete dias, o tema mudava e as melhores fotos apareciam no jornal impresso, no "Focoblog" (blog da editoria de Fotografia) e em outros veículos do Grupo RBS.

Guidotti (2015) explica que os projetos \#doleitorZH e \#missão$\mathrm{ZH}$ visam a criar vínculos com o público:

O usuário/leitor de redes sociais interessa-se por aquilo que lhe é próximo, que lhe diz respeito. Diante do exposto pode-se imaginar que esses projetos colaborativos possam contribuir para um aumento do número de seguidores, de likes e da popularidade desses veículos em geral. (GUIDOTTI, 2015, p. 12)

Durante o levantamento, verificou-se a predominância de registros no Rio Grande do Sul, sendo 95 fotos e um vídeo, o que corresponde a 94\%. Em relação aos demais estados, encontramos publicações de paisagens em quatro fotografias e um vídeo de Santa Catarina e em uma imagem de São Paulo. Isso demonstra que o perfil no Instagram reforça a construção da identidade gaúcha, que, segundo Ângela Felippi (2006), é uma estratégia mercadológica de todos produtos do Grupo RBS desde sua fundação, fortalecida por meio da visibilidade aos aspectos da cultura local, que "coincide com a emergência dos movimentos culturais tradicionalista e nativista, ocorridos no estado nos anos 80" (FELIPPI, 2006, p. 23).

Em sua pesquisa doutoral, a autora comprovou que a RBS tem se voltado para as questões da identidade gaúcha. No caso do jornalismo e das campanhas comunitárias, há uma busca pela aproximação da "comunidade gaúcha" e que, assim como acorreu na política desenvolvida pelo grupo em Santa Catarina, pretende-se criar vínculos e fortalecer o sentimento de pertencimento ao estado de atuação.

Quanto ao cenário das publicações, $76 \%$ são de paisagens naturais (sendo 77 fotos e um vídeo) e $24 \%$ de espaços urbanos (sendo 
23 fotos e um vídeo). Para a referida categoria, nos baseamos nos conceitos de Ferreira e Padilha $(2014)^{23}$, que descrevem as fotos de paisagem/natureza sendo de praias, árvores, nuvens, entre outras, demonstrando que as "múltiplas possibilidades de enfoques, a sutileza dos enquadramentos e a beleza de suas composições permitem um olhar que agrega diversos aspectos sobre a relação homem/natureza" (FERREIRA; PADILHA, 2014, p. 122). Os autores também expõem que cliques de cidades e prédios representam as atividades cotidianas e retratam os costumes, culturas e grupos sociais que ali pertencem.

Observamos, ainda, que as alternativas no projeto possuem elementos que giram em torno do pertencimento simbólico (SILVA JÚNIOR, 2012), criando aproximação entre a marca e sua audiência. Assim, no período de análise, deu-se destaque nas publicações que mostraram cuia e bomba de chimarrão, animais de estimação e/ou fizeram referência ao Grêmio (tradicional time de futebol gaúcho) ${ }^{24}$.
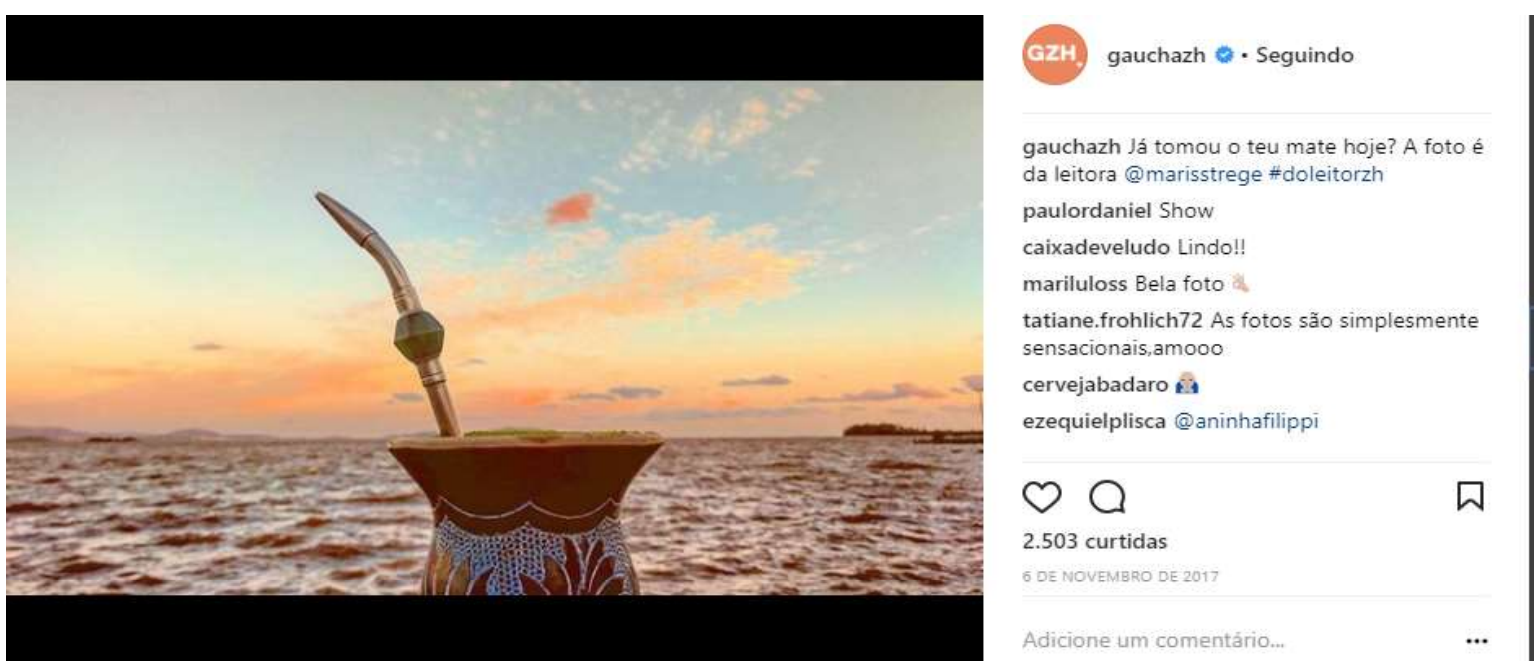

23 Em estudo semelhante, Ferreira e Padilha (2014) identificaram os cenários registrados no projeto \#AmanhecerEstadao, criado pelo jornal O Estado S. Paulo no Instagram. Das 66 fotografias categorizadas entre os meses de dezembro de 2013 a fevereiro de 2014, os autores encontraram uma amostragem maior de cliques de cidades e prédios ( 40 fotos, equivalendo a $60 \%$ ) do que da natureza e suas paisagens ( 26 fotos, equivalendo a $40 \%$ ).

24 No dia 29 de novembro de 2017, o Grêmio tornou-se tricampeão da Copa da Libertadores da América. 0 título veio após a vitória por 2 a 1 contra o Lanús, no estádio La Fortaleza, na Argentina. 

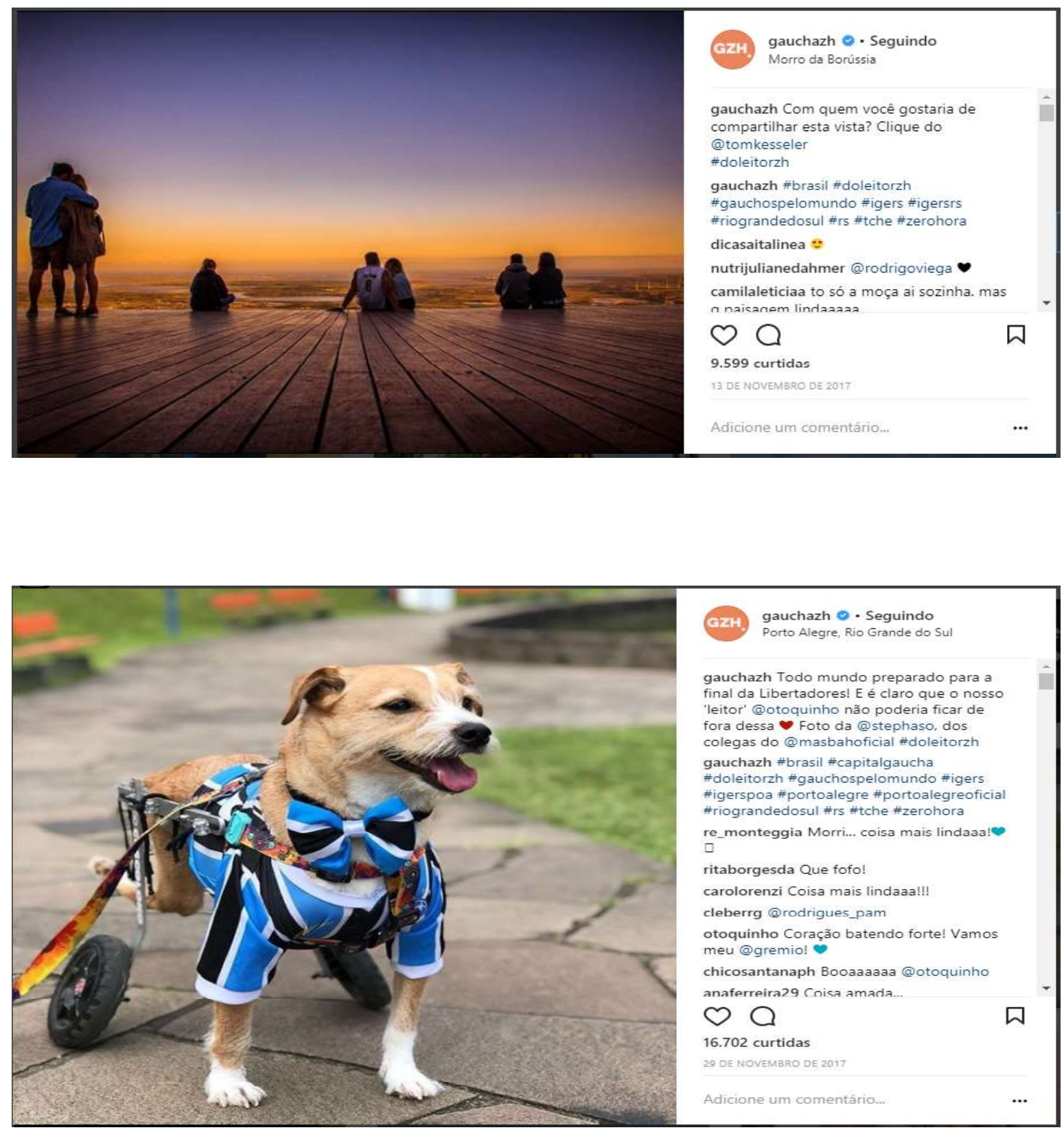

Figuras 1, 2 e 3: Exemplos de publicações que foram destaques no projeto \#doleitorZH Fonte: Instagram Gaúcha ZH

Contudo, embora os dados apontem a existência da cultura participativa (JENKINS, 2009), a marca opta por registros profissionais. Dos 84 autores na \#doleitorZH, 64 utilizam o Instagram para divulgar seus trabalhos fotográficos, constatado no perfil dos próprios usuários. Cabe pontuar que, para Vieira (2015), fotógrafos profissionais e amadores visualizam as novas possibilidades de comunicação disponíveis em um ambiente aberto e popular. 
Os fotojornalistas estão usando o aplicativo de compartilhamento de fotos especialmente para dividir com o mundo seus projetos, da forma mais rápida e influente que temos nos dias de hoje. Essa nova onda de usuários está gerando excelente imagens no aplicativo e seguir esses profissionais é uma ótima forma de acompanhar o que está acontecendo no mundo. (VIEIRA, 2015, p. 9)

O Zero Hora estimula a participação desses fotógrafos divulgando os autores em todas as publicações compartilhadas. No entanto, o leitor "comum", que não domina técnicas mais sofisticadas de tratamento de imagem, cede espaço para os fotojornalistas, já que "as imagens de belas paisagens, imagens esteticamente bem elaboradas, que facilmente ganham o 'coração' dos usuários" (GUIDOTTI, 2017, p. 9), conseguem um engajamento com mais curtidas e comentários.

O projeto contribui com a composição harmoniosa do perfil, por isso valoriza publicações de caráter artístico, que trazem cores vibrantes, cenários bem elaborados e edições qualificadas. Deste modo, em busca de um discurso visual original são negligenciados dois traços marcantes da plataforma: a instantaneidade e a praticidade na produção e distribuição fotográfica. Apesar das mudanças trazidas pelo Instagram no fotojornalismo, aos poucos, "há um retorno ao antigo modo de fazer fotojornalismo, com a utilização de câmeras profissionais e o abandono dos filtros e dos dispositivos móveis como principais ferramentas de obtenção das imagens" (GUIDOTTI, 2017, p. 9).

No ponto sobre a geolocalização, o check-in foi realizado em 68 fotos, equivalendo a $66 \%$. Em oito publicações, o local não está identificado propositalmente, pois nas legendas constam perguntas com a finalidade de os usuários as responderem nos comentários. Essa estratégia de interação está demonstrada abaixo:

1. "Desafio: alguém adivinha onde a @tempusfrangit tirou essa foto?" (6 de novembro de 2017);

2. "Desafio nível difícil: você consegue adivinhar onde o @xexeusiqueira tirou essa foto?" (7 de novembro de 2017);

3. "Desafio: Quem adivinha onde o @wikler.shots tirou essa foto? 
(13 de novembro de 2017);

4. “Desafio: alguém sabe onde o @gesiel_freire tirou essa foto?” (15 de novembro de 2017);

5. "Parece Europa, mas é o nosso belo Rio Grande do Sul! Algum palpite do lugar que o leitor @jacsinhermann tirou essa bela foto?” (16 de novembro de 2017);

6. "Desafio em dia de chuva: quem adivinha onde o @topfernando tirou essa foto?" (16 de novembro de 2017);

7. “Alguém adivinha onde o @tomkesseler tirou essa foto?” (20 de novembro de 2017);

8. "Você consegue adivinhar o local que a leitora@marinatureza tirou essa bela foto? (27 de novembro de 2017).

Também percebemos que a marca usou outras hashtags nos comentários de 82 fotos e um vídeo, correspondendo a $81 \%$. Verificamos a ocorrência de \#brasil, \#capitalgaucha, \#gauchospelomundo, \#igers, \#igerspoa, \#portoalegre, \#\#portoalegreoficial, \#riograndedosul, \#rs, \#tche e \#zerohora. Desta maneira, além do poder estético e informacional, o projeto utiliza outras potencialidades da mídia digital, possibilitando novas formas de conexão e interação com os conteúdos do perfil.

\section{Considerações finais}

As dimensões imagéticas materiais, simbolizadas pelas representações visuais, operalizam na dimensão biológica e sociocultural em ininterrupta relação a partir da dimensão tecnológica (AUMONT, 2006). No caso da fotografia jornalística, acredita-se na conexão entre as imagens e a concepção de realidade, a qual, para Sousa (2000), permite que as múltiplas possibilidades informativas sejam visualizadas junto à notícia e suas guias.

Ao considerar que vivenciamos o paradigma pós-fotográfico (SANTAELLA; NÖTH, 2001), destacamos o Instagram como um aplicativo que trouxe diferente modo entre fazer e ver fotografia, sintetizando "em modelo operacional o regime visual do começo do século XXI" (SILVA JÚNIOR, 2014). Como novas formas de apropriação, os veículos de comunicação utilizam a plataforma para divulgar conteúdo e interagir com o público. 
Em relação ao que foi exposto, destacamos o @gauchaZH, perfil da marca Zero Hora no Instagram. Nele, avaliamos o uso do projeto \#doleitorZH, idealizado desde 2012 e envolve a participação dos usuários no feed da organização jornalística. Tendo como aporte metodológico a análise de conteúdo (BARDIN, 2011), a coleta de dados abrangeu o período de 30 dias, em novembro de 2017. Das 197 mídias encontradas, 102 estão categorizados pela hashtag estudada, o que corresponde a $52 \%$.

Outro projeto também foi realizado pelo $\mathrm{ZH}$ na plataforma, o \#missãoZH, que solicitava o envio das fotos a partir de temas previamente definidos pela equipe do jornal. Isso demonstra que o perfil @gauchaZH procura sempre inovar nas publicações tanto do Instagram quanto das demais redes sociais (Facebook e Twitter) e, por isso, recebeu o prêmio de Melhor Uso de Redes Sociais, no Global Media Awards da International News Media Association (INMA), em maio de 2017. A empresa, que lançou o seu primeiro site na internet em 1995 (GRUSZYNSKI; LINDEMANN; OLIVEIRA, 2014), busca adequar-se ao contexto da convergência.

As publicações na \#doleitorZH possuem um forte apelo estético e são registradas, principalmente, por fotógrafos profissionais, deixando de lado a instantaneidade e a praticidade na produção e distribuição fotográfica. Portanto a competição por popularidade no aplicativo, manifestada na quantidade de curtidas e comentários, gera "uma concorrência estética que faz com que muitos usuários abandonem a produção de fotografias no smartphone e passem a utilizar as câmeras profissionais para a captura, restringindo o uso do smartphone apenas à publicação" (GUIDOTTI, 2015, p. 10).

Em contrapartida, o projeto dá preferência aos ângulos registrados no Rio Grande do Sul, aumentando a relação do Zero Hora com o seu leitor (e, mais recentemente, com o público da Rádio Gaúcha), que se identifica com o conteúdo compartilhado pelo perfil e reforça a identidade gaúcha (FELIPPI, 2006). As notícias jornalísticas são disponibilizadas por meio da ferramenta Instagram Stories. Destarte, a marca trabalha com o Instagram de diferentes maneiras, explorando melhor suas potencialidades. 


\section{REFERÊNCIAS}

AUMONT, J. A imagem. Campinas, SP: Papirus, 2006.

BARBALHO, M. Foto + vídeo + jornalismo: uma nova forma de testemunhar o mundo. In: SEMINÁRIO DE ALUNOS DE PÓS-GRADUAÇÃO EM COMUNICAÇÃO, Rio de Janeiro-RJ, 2011. Anais... Disponível em: $<$ http://poscom.com.puc-rio.br/arquivos/pdfs/2011/entremeios/Marcelo_Barbalho_GT_Imagens_e_Representacao_no_Audiovisual.pdf $>$. Acesso em 03 de fevereiro de 2018.

BARDIN, L. Análise de conteúdo. 6 ed. São Paulo: Edições 70, 2011.

BARTHES, R. O óbvio e o obtuso. Rio de Janeiro: Nova Fronteira, 1990.

BATISTA, E. Jornalismo no Instagram? Como os grandes veículos jornalísticos utilizam as redes sociais no ciberespaço, 58f. Trabalho de Conclusão de Curso (Bacharel em Comunicação Social - Habilitação em Jornalismo). Universidade Federal de Juiz de Fora - UFJF. Juiz de Fora-MG, 2014.

FERREIRA, J. Mídia e conhecimento: objetos em torno do conceito de dispositivo. In: XXV CONGRESSO BRASILEIRO DE CIÊNCIAS DA COMUNICAÇÃO, Salvador-BA, 2002. Anais... Disponível em: <http:// www.portcom.intercom.org.br/pdfs/109656372301436113128775687547 030747230.pdf >. Acesso em 03 de fevereiro de 2018.

FERREIRA, J.; PADILHA, A. O Estadão no Instagram: do jornal impresso ao aplicativo móvel. In: Comunicação \& Mercado/UNIGRAN, v. 03, n. 08, jul./dez. 2014.

GUIDOTTI, F. G. Delineamentos e reflexões sobre o uso do Instagram em jornais brasileiros de grande circulação. In: XXXVIII CONGRESSO BRASILEIRO DE CIÊNCIAS DA COMUNICAÇÃO, Rio de Janeiro-RJ, 2015. Anais... Disponível em: <http://portalintercom.org.br/anais/nacional2015/resumos/R10-3282-2.pdf>. Acesso em 03 de fevereiro de 2018.

. Fotojornalismo no Instagram. O que os usuários querem ver? 
In.: XVIII CONGRESSO DE CIÊNCIAS DA COMUNICAÇÃO NA REGIÃO SUL, Caxias do Sul-RS, 2017. Anais... Disponível em: <http://portalintercom.org.br/anais/sul2017/resumos/R55-0572-1.pdf >. Acesso em 03 de fevereiro de 2018.

GRUSZYNSKI, A. C.; LINDEMANN, C.; OLIVEIRA, C. de. Virando-se por leitores: a reforma editorial e gráfica do jornal Zero Hora no cenário de convergência. In: XXXVII CONGRESSO BRASILEIRO DE CIÊNCIAS DA COMUNICAÇÃO, Foz do Iguaçu-PR., 2014. Anais... Disponível em: <http://www.intercom.org.br/papers/nacionais/2014/resumos/ R9-0718-1.pdf $>$. Acesso em 03 de fevereiro de 2018.

FELIPPI, Â. C. T. Jornalismo e identidade cultural. Construção da identidade gaúcha em Zero Hora. Tese (Doutorado em Comunicação Social). Programa de Pós-Graduação em Comunicação Social, Pontifícia Universidade Católica do Rio Grande do Sul, Porto Alegre, 2006.

JENKINS, H. Cultura da convergência: a colisão entre os velhos e novos meios de comunicação. São Paulo: Aleph, 2009.

JOLY, M. Introdução a uma análise da imagem. Campinas: Papirus, 2006.

LISBOA, A.; FREIRE, G. Do Instantâneo aos Filtros: A Estética Fotográfica do Instagram. In: Temática, n. 5, maio-2014

LINDEMANN, C. O jornal Zero Hora e seus leitores no contexto da convergência jornalística. Tese (Doutorado em Comunicação e Informação). Programa de Pós-graduação em Informação, Universidade Federal do Rio Grande do Sul, Porto Alegre, 2014.

LUZ, A. L. L. da. @transmidia: perfil jornalístico no Instagram com pautas sobre a transexualidade, 115f. Trabalho de Conclusão de Curso (Bacharel em Jornalismo). Universidade Estadual de Ponta Grossa - UEPG. Ponta Grossa-PR, 2017.

PIRES, G. T. S. Fotografia através de dispositivos móveis: Estudo de caso sobre o Instagram. In: Revista da Graduação, v. 6, n. 1, 2013. 
PRIMO, A. Interação mediada por computador: comunicação, cibercultura, cognição. Porto Alegre: Sulina, 2007.

RECUERO, R. Redes sociais na Internet. Porto Alegre: Sulina, 2009.

RUVIARO, R. P.; BELOCHIO, V de. C. Jornalismo em redes sociais: o InstaStories como mídia diferenciada para o acesso à informação em @ zerohora. In: XVIII CONGRESSO DE CIÊNCIAS DA COMUNICAÇÃO NA REGIÃO SUL, Caxias do Sul, 2017. Anais... Disponível em: <http:// portalintercom.org.br/anais/sul2017/resumos/R55-0597-1.pdf $>$. Acesso em 15 de outubro de 2018.

SALAVERRÍA, R.; GARCIA AVILÉS, J.; MASIP, P. Concepto de Convergencia de Medios. In: LOPEZ, X.; PEREIRA, X. (orgs). Convergencia Digital: Reconfiguración de los Medios de Comunicación en España. Santiago de Compostela: Servizo de Publicacións e Intercambio Científico, 2010.

SANTAELLA L.; NÖTH, W. Imagem - cognição, semiótica e mídia. São Paulo: Iluminuras, 2001.

SILVA JÚNIOR, J. A. da. Entre o Instagram e a Kodak. Expansões e ultrapassagens na cultura fotográfica contemporânea. In: Esferas, n. 5, jul./ dez. 2014.

SOUSA, J. Uma história crítica do fotojornalismo ocidental. Chapecó: Grifos; Florianópolis: Letras Contemporâneas, 2000.

VIEIRA, T. de M. A fotografia e as novas mídias: como o Instagram alterou a forma de produzir imagens. In: XXXVIII CONGRESSO BRASILEIRO DE CIÊNCIAS DA COMUNICAÇÃO, Rio de Janeiro-RJ, 2015. Anais... Disponível em: <http://portalintercom.org.br/anais/nacional2015/resumos/R10-2593-1.pdf $>$. Acesso em 03 de 